\section{Analisis Produktivitas Waktu KerJa Alat BERAT PADA PEMbangunan LANJUTAN REKLAMASI DAN JALAN KAWASAN KAYU MERAH- KALUMATA}

\author{
M. Irsan Sangadjii ${ }^{\mathrm{a}}$ Edward Rizky Ahadian ${ }^{\mathrm{b} *}$, M. Darwis ${ }^{\mathrm{c}}$ \\ abcUniversitas Khairun, Ternate, Indonesia
}

Article history

Received

10 Januari 2020

Received in revised form

2 Pebruari 2020

Accepted

5 Maret 2020

*Corresponding author edward.rizky@unkhair.ac.id

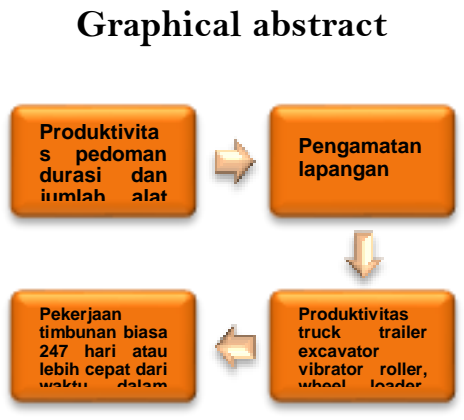

\begin{abstract}
The development of the construction world has resulted in the increasing need for heavy equipment for each project. Heavy equipment is a vital resource in a construction project. However, the costs required to procure heavy equipment are not cheap. Therefore, the choice of heavy equipment has a big influence on the efficiency and profitability of construction work. Productivity is used as a guide in determining the duration of each job and the number of heavy equipment to be treated. This research was conducted by observing the field to obtain the time needed by each heavy equipment in the reclamation work which then carried out the calculation of productivity. The results of the research are that the trailer/trailer truck has a productivity of 60.614 minutes, the excavator has a productivity of $21 \mathrm{~m}^{3} /$ hour, the roller vibrator has a productivity of $155.625 \mathrm{~m}^{3} /$ hour, the wheel loader has a productivity of $91.098 \mathrm{~m}^{3}$ hour, the water tanker has a productivity of $14.229 \mathrm{~m}^{3} /$ hour, the motor grader has a productivity is $942,880 \mathrm{~m}^{2} /$ hour, and the dump truck has a productivity of 26,981 $\mathrm{m}^{3} /$ hour, then after analyzing the productivity of heavy equipment the next stage is calculating the time efficiency that occurs in each work item, and the mobilization work takes 17 days or less than the expected time. it has been planned in the contract document that is 28 days, in the usual piling work from the excavation source it will take 247 days or less than the time planned in the contract document which is 287 days.
\end{abstract}

Keywords: Equipment Productivity, Working Time, Heavy Equipment.

\begin{abstract}
Abstrak
Perkembangan dunia konstruksi mengakibatkan semakin tingginya tingkat kebutuhan alat berat pada setiap proyek. Alat berat merupakan sumber daya vital pada proyek konstruksi. Namun biaya yang dibutuhkan untuk pengadaan alat berat tidaklah murah. Oleh sebab itu pemilihan alat berat memberikan pengaruh yang besar terhadap efisiensi dan profitabilitas pada pekerjaan konstruksi. Produktivitas digunakan sebagai pedoman dalam menentukan durasi pelaksanaan setiap pekerjaan dan jumlah alat berat yang diperlakukan. Penelitian ini dilakukan dengan pengamatan dilapangan untuk mendapatkan waktu yang dibutuhkan oleh setiap alat berat pada pekerjaan reklamasi yang selanjutnya dilakukan perhitungan produktivitas. Hasil penelitian alat truck trailer/tronton memiliki produktivitas 60,614 menit, excavator memiliki produktivitas $21 \mathrm{~m}^{3} / \mathrm{jam}$, vibrator roller memiliki produktivitas $155,625 \mathrm{~m}^{3} / \mathrm{jam}$, wheel loader memiliki produktivitas $91,098 \mathrm{~m}^{3} / \mathrm{jam}$, water tanker memiliki produktivitas $14,229 \mathrm{~m}^{3} / \mathrm{jam}$, motor grader memiliki produktivitas $942,880 \mathrm{~m}^{2} / \mathrm{jam}$, dan dump truck memiliki produktivitas $26,981 \mathrm{~m}^{3} / \mathrm{jam}$, kemudian setelah dilakukan analisis produktivitas alat berat tahap selanjutnya yaitu menghitung efisiensi waktu yang terjadi pada setiap item pekerjaan, dan pada pekerjaan mobilisasi membutuhkan waktu 17 hari atau lebih cepat dari waktu yang telah direncanakan dalam dokumen kontrak yaitu 28 hari, pada pekerjaan timbunan biasa dari sumber galian membutuhkan waktu 247 hari atau lebih cepat dari waktu yang direncanakan dalam dokumen kontrak yaitu 287 hari
\end{abstract}

Kata kunci: Produktivitas Alat, Waktu Kerja, Alat Berat

(C) 2021 Penerbit Fakultas Teknik Unkhair. All rights reserved 


\subsection{PENDAHULUAN}

Perkembangan dunia konstruksi mengakibatkan semakin tingginya tingkat kebutuhan alat berat pada setiap proyek konstruksi, (Peurifoy, 2006). Namun biaya yang dibutuhkan untuk pengadaan alat berat tidaklah murah. Oleh sebab itu, pemelihan alat berat memberikan pengaruh yang besar terhadap efisiensi dan profitabilitas pada pekerjaan konstruksi, (Nunnaly, 2007).

Untuk mengetahui tingkat efisiensi dan efektivitas sebuah alat berat yang diperlukan besaran yang dinyatakan dengan produktivitas alat. Produktivitas digunakan sebagai pedoman dalam menentukan durasi pelaksanaan setiap pekerjaan dan jumlah alat berat yang diperlukan. Berbagai faktor dapat mempengaruhi produktivitas suatu alat berat, maka diperlukan pengamatan lapangan terhadap aktivitas alat berat selama untuk dapat memperoleh nilai produktivitas alat berat.

Alat berat dikatakan produktif apabila selama jam kerja alat berat tersebut terus bekerja sesuai dengan fungsi dan tujuan dari alat berat tersebut, dan dalam pelaksanaan proyek dilapangan tidak dikerjakan sesuai dengan jumlah alat berat yang direncanakan dan perubahan yang dilakukan tidak disertai dengan perhitungan produktivitas yang dapat dihasilkan.

\section{Alat Berat}

Alat-alat berat yang dikenal didalam ilmu teknik sipil adalah alat yang digunakan untuk membantu manusia dalam melakukan pekerjaan pembangunan suatu struktur atau suatu alat yang dapat melipat gandakan jasa manusia untuk mencapai usahanya. Pemilihan alat berat yang akan dipakai merupakan salah satu faktor penting dalam keberhasilan suatu manajemen proyek. Tujuan dari penggunaan alat-alat berat tersebut adalah untuk memudahkan manusia dalam mengerjakan pekerjaannya, sehingga hasil yang di harapkan dapat tercapai dengan lebih mudah dengan waktu yang relative lebih singkat (Rochmanhadi, 1985).

Menurut (Susy Fatena Rostiyanti, 2008) dalam bukunya alat berat proyek konstruksi, menyebutkan bahwa bonafiditas suatu perusahan konstruksi tergantung dari asset-aset teknologi yang di milikinya, salah satunya adalah alat berat. Alat berat yang di miliki sendiri oleh perusahan konstruksi akan sangat menguntungkan dalam memenangkan tender proyek konstruksi secara otomatis hal tersebut akan mencerminkan kekuatan perusahan tersebut.

Alat berat pada penilitian ini terbagi atas :

1. Alat penggerak utama atau alat berat, yaitu: Excavator, Vibrator Roller, Wheel Loader, Water Tanker, Motor Grader.

2. Alat-alat tambahan, yaitu: Dump Truck, Peralatan Survey (Theodolit, Waterpass, dan GPS), Peralatan Laboratorium Tanah, Peralatan Laboratorium Aspal, dan lain-lain.

\section{Manajemen Alat Berat}

Pemilihan alat berat dilakukan pada tahap perencanaan, dimana jenis, jumlah, dan kapasitas alat merupakan faktor-faktor penentu. Tidak setiap alat berat dapat dipakai untuk setiap proyek konstruksi. Oleh karena itu pemilihan alat berat yang tepat sangatlah diperlukan. Apabila terjadi kesalahan dalam pemilihan alat berat maka akan terjadi keterhambatan di dalam pelaksanaannya, biaya proyek yang membengkak, dan hasil tidak sesuai dengan rencana waktu yang ditentukan.

Didalam pemilihan alat berat, ada beberapa faktor yang harus diperhatikan sehingga kesalahan dalam pemilihan alat dapat dihindari. Faktor-faktor tersebut antara lain sebagai berikut :

berikut :

1. Fungsi yang harus dilaksanakan. Alat berat dikelompokkan berdasarkan fungsinya, seperti untuk menggali, mengangkut, meratakan permukaan, dan lain-lain.

2. Kapasitas peralatan. Pemilihan alat berat didasarkan pada volume total atau berat material yang harus diangkut atau dikerjakan. Kapasitas alat yang harus sesuai sehingga pekerjaan dapat diselesaikan pada waktu yang telah ditentukan.

3. Cara operasi. Alat berat dipilh berdasarkan arah (horizontal maupun vertikal) dan jarak gerakan, kecepatan, frekuensi gerakan, dan lain-lain.

4. Pembatasan dari metode yang di pakai. Pembatasan yang mempengaruhi pemilihan alat berat antara lain peraturan lalu lintas, biaya, dan pembongkaran. Selain itu metode konstruksi yang di pakai dapat membuat pemilihan alat berat berubah.

5. Ekonomi. Selain biaya investasi atau biaya sewa peralatan, biaya operasi dan biaya pemeliharaan merupakan faktor penting di dalam pemilihan alat berat pada suatu proyek konstruksi.

6. Jenis proyek. Ada beberapa jenis proyek yang umumnya menggunakan alat berat. Proyek-proyek tersebut antara lain proyek jembatan, gedung, pelabuhan, jalan, bandar udara, irigasi, pembuka hutan, dan sebagainya.

7. Lokasi proyek. Lokasi proyek juga merupakan hal lain yang perlu diperhatikan dalam pemilihan alat berat. Sebagai contoh lokasi proyek didataran tinggi memerlukan alat berat yang berbeda dengan lokasi proyek di dataran rendah.

8. Jenis dan daya dukung tanah. Jenis tanah di lokasi proyek dan jenis material yang akan di kerjakan dapat mempengaruhi alat berat yang akan dipakai, tanah dapat dalam kondisi padat, lepas, keras, atau lembek. 
9. Kondisi lapangan. Kondisi lapangan dengan medan yang sulit dan medan yang baik meupakan factor lain yang mempengaruhi pemilihan alat berat.

\subsection{METODE PENELITIAN}

Jenis penelitian yang dilakukan menggunakan penelitian kuantitatif, penelitian ilmiah yang sistematis terhadap bagian-bagian dan hubungan-hubungannya. Tujuan penelitian kuantitatif adalah mengembangkan dan menggunakan model-model matematis, teori-teori dan hipotesis. Penelitian ini dilakukan \pm 3 bulan yaitu Desember 2019 sampai Februari 2020 dan berlokasi di Kelurahan Kalumata, Kota Ternate, Maluku Utara

\subsection{Teknik Pengumpulan Data}

Pelaksanaan penelitian ini dilakukan dengan beberapa tahap, yaitu :

1. Persiapan

Membuat surat permohonan pengambilan data yang ditujukan kepada instansi terkait. Tahap ini juga diikuti dengan mengumpulkan referensi yang berhubungan dengan penelitian ini.

2. Pengumpulan data

Guna menghitung besarnya produktivitas aktual, sebagaimana dikemukakan di atas diperlukan sejumlah data. Data yang sudah terkumpul lebih lanjut disesuaikan jenisnya dengan menggunakan teori-teori literature. Sesuai dari volume yang di dapat, selanjutnya dianalisis produktivitas peralatan dan waktu siklus dengan memperhatikan kendala-kendala yang ada. Dengan didapatkan unsur-unsur di atas menurut saya memperolehnya ada dua jenis data, yaitu data primer dan data sekunder.

a. Data primer, adalah data yang didapatkan melalui pengamatan langsung wawancara dengan pihak terkait atau hasil penilitian terhadap suatu objek, yang termasuk kategori data primer adalah :

- Pengamatan waktu yang dibutuhkan di lapangan untuk peralatan truck trailer/tronton, excavator, vibrator roller, wheel loader, water tanker, motor grader dan dump truck.

- Jam kerja peralatan di mulai dari pagi jam 07.00 WIT dan berakhir pada sore hari jam 17.00 WIT (8 jam kerja efektif).

b. Data sekunder adalah data yang sudah ada yang diperoleh pada suatu badan atau instansi dan dapat langsung dipakai tanpa perlu pengolahannya yaitu data peralatan alat-alat berat.

\subsection{HASIL DAN PEMBAHASAN}

\subsection{Hasil Perhitungan Alat Berat}

Hasil yang diperoleh dari pengolahan data dan pembahasan yang mengacu pada teori-teori serta pembahasan dari pokok permasalahan. Setiap peralatan mempunyai kemampuan produktivitas tertentu. Penyebab produktivitas peralatan yang sama untuk setiap kali pengoperasiannya disebabkan oleh adanya faktor-faktor hambatan. Faktor hambatan dapat berupa kemampuan operator, keadaan jenis material, situasi lokasi kerja dan tata cara dari masing-masing elemen gerakan dilakukan penilitian dan pengukuran langsung di lapangan nantinya.

\subsection{Produktivitas Alat Pada Pekerjaan Mobilisasi}

Metode Kerja dilapangan :

1. Mendatangkan peralatan ke lokasi.

2. Menyiapkan personil/pekerja dilapangan.

3. Menyiapkan perlengkapan untuk melaksanakan semua item pekerjaan dilapangan.

Alat yang digunakan :

1. Truck Trailer/Tronton 1 unit, dengan mekanisme kerja mengangkut alat berat lain ke lokasi proyek.

2. Excavator 6 unit, dengan mekanisme kerja mengali, mengangkat maupun memuat material.

3. Vibrator Roller 2 unit, dengan mekanisme kerja memadatkan tanah yang telah ditimbun.

4. Wheel Loader 2 unit, dengan mekanisme kerja membantu memuat material ke dalam dump truck.

5. Water Tanker 2 unit, dengan mekanisme kerja mengangkut air yang digunakan untuk menyiram permukaan material yang dipadatkan.

6. Motor Grader 2 unit, dengan mekanisme kerja memotong atau meratakan suatu permukaan tanah.

7. Dump Truck 28 unit, dengan mekanisme kerja mengangkut material dari lokasi galian menuju ke lokasi timbunan. 


\subsection{Produktivitas Alat Pada Pekerjaan Timbunan Biasa dari Sumber Galian}

\section{Metode Kerja :}

1. Melakukan persiapan lokasi pekerjaan.

2. Memuat material timbunan biasa dari sumber galian dengan menggunakan dump truck.

3. Timbunan biasa dihampar dengan menggunakan motor grader.

4. Hasil hamparan timbunan biasa disiram air dengan menggunakan water tanker kemudian dipadatkan dengan menggunakan vibrator roller sampai mencapai ketebalan dan kepadatan sesuai dengan spesifikasi yang ditentukan.

5. Melakukan pengujian timbunan.

6. Perapihan hasil pekerjaan, setiap material sisa diangkut untuk dibuang pada area yang ditentukan.

Alat yang digunakan :

1. Excavator 6 unit, dengan mekanisme kerja mengali, mengangkat maupun memuat material.

2. Dump Truck 28 unit, dengan mekanisme kerja mengangkut material dari lokasi galian menuju ke lokasi timbunan.

3. Motor Grader 2 unit, dengan mekanisme kerja memotong atau meratakan suatu permukaan tanah.

4. Vibrator Roller 2 unit, dengan mekanisme kerja memadatkan tanah yang telah ditimbun.

5. Water Tanker 2 unit, dengan mekanisme kerja mengangkut air yang digunakan untuk menyiram permukaan material yang dipadatkan.

\subsection{Hasil Perhitungan Produktivitas Alat Berat :}

\section{a. Produksi Truck Trailer / Tronton}

Merek / type

Panjang Dek Kerja (V1)

Lebar Dek Kerja (V2)

Jarak angkut (L)

: Mitshubishi Fuso 6X4 / FN 62 FL HD

: $9,5 \mathrm{~m}$

$: 2,5 \mathrm{~m}$

$: 10,000 \mathrm{~m}$

Kec. Rata-rata bermuatan $(\mathrm{V} 1) \quad: 30 \mathrm{~km} / \mathrm{jam}=500 \mathrm{~m} / \mathrm{menit}$ (tabel.2)

Kec. Rata-rata kosong $(\mathrm{V} 2) \quad: 50 \mathrm{~km} / \mathrm{jam}=833,333 \mathrm{~m} /$ menit (tabel.2 )

Faktor efisiensi kerja (E)

: 0,83 (tabel 1.)

Waktu siklus $(\mathrm{Cm})$ :

$>$ Waktu muat (LT)

jumlah siklus yang dibutuhkan alat pemuat tronton.

cms alat pemuat (excavator) $=0,90$

Waktu angkut (T1)

$$
\mathrm{N}=\frac{\text { Panjang Dek } \times \text { Lebar Dek }}{\text { Faktor Efisiensi Kerja }} \mathrm{N}=\frac{9,5 \times 2,5}{0,83}=28,614
$$

$$
=\frac{\mathrm{L}}{\mathrm{V} 1}=\frac{10,000 \mathrm{~m}}{500 \frac{\mathrm{m}}{\mathrm{jam}}}=20 \text { menit }
$$

Waktu kembali (T2)

$$
=\frac{\mathrm{L}}{\mathrm{V} 2}=\frac{10,000 \mathrm{~m}}{833,333 \mathrm{~m} / \mathrm{jam}}=12 \text { menit }
$$

$$
\text { Jadi : } \begin{aligned}
\mathrm{Cm} & =\mathrm{LT}+\mathrm{T} 1+\mathrm{T} 2 \\
& =28,614+20+12 \\
& =60,614 \text { menit }
\end{aligned}
$$

\section{b. Produksi Excavator}

Merek / type

Kapasitas Bucket (KB)

Faktor bucket

Faktor kesiapan mesin

$$
\begin{aligned}
& : \text { Komatsu PC } 200 \\
& : 1,00 \mathrm{~m}^{3} \\
& : 0,90 \\
& : 0,75
\end{aligned}
$$


Faktor efisiensi kerja dilapangan

Faktor efisiensi operator

Faktor efisiensi waktu

Faktor koreksi (FK)

Menggali / memuat

Lain - lain

Waktu siklus (Cm)

Taksiran Produksi Alat (Q)

$$
\begin{aligned}
Q & =\frac{K B \times 60 \times F K}{C m} \\
& =\frac{1,00 \times 60 \times 0,315}{0,90}=21 \mathrm{~m}^{3} / \mathrm{jam}
\end{aligned}
$$

c. Produksi Vibrator Roller

Merek / Tipe

Kecepatan rata-rata $(\mathrm{V})$

Lebar efektif pemadatan (W)

Jumlah lintasan (n)

Tebal efektif rata-rata $(\mathrm{t})$

Efisiensi alat (E)

Taksiran Produksi Alat (Q)

$$
\begin{aligned}
Q & =\frac{W \times V \times 1000 \times E}{n} \\
& =\frac{0,3 \times 2,5 \times 1000 \times 0,83}{4} \\
& =155,625 \mathrm{~m}^{3} / \mathrm{jam}
\end{aligned}
$$

: Bomag BW. 212

: $2,5 \mathrm{~km} / \mathrm{jam}$ (tabel 7)

: 0,3 (tabel 8)

: 4 lintasan (tabel 9)

: $0,10 \mathrm{~m}$

: 0,83 (tabel. 1)

\section{d. Produksi Wheel Loader}

Merk / Tipe

Kapasitas Bucket (KB)

Faktor Bucket (E)

Jarak kerja (D)

Kec. Maju (F)

Kec. Mundur (R)

Waktu Tetap $(Z)$

Efisiensi alat (E)

Metode operasi V (Shape Load)

Waktu siklus $(\mathrm{Cm})$

$$
\begin{aligned}
& : \text { Caterpillar 966-C HP.150 } \\
& : 1,50 \mathrm{~m}^{3} \\
& : 0,83(\text { tabel 11) } \\
& : 10 \mathrm{~m} \\
& : 6 \mathrm{~km} / \mathrm{jam} \times 0.8=4,8 \mathrm{~km} / \mathrm{jam} \\
& \quad=80 \mathrm{~m} / \mathrm{menit} \\
& : 4 \mathrm{~km} / \mathrm{jam} \times 0.8=3,2 \mathrm{~km} / \mathrm{jam} \\
& \quad=53,333 \mathrm{~m} / \mathrm{menit} \\
& : 0,20(\text { tabel } 11) \\
& : 0,83(\text { tabel } 1) \\
& : 2
\end{aligned}
$$

$$
\begin{aligned}
& \qquad \begin{aligned}
\mathrm{Cm}=2 \frac{\mathrm{D}}{\mathrm{F}}+2 \frac{\mathrm{D}}{\mathrm{R}} & +\mathrm{Z} \\
& =2 \frac{10 \mathrm{~m}}{80 \mathrm{~m} / \mathrm{menit}}+2 \frac{10 \mathrm{~m}}{53,333 \mathrm{~m} / \mathrm{menit}}+0,20
\end{aligned} \\
& =0,820 \text { menit }
\end{aligned}
$$

$\underline{\text { Taksiran Produksi Alat (Q) }}$

$$
\mathrm{Q}=\frac{\mathrm{KB} \times 60 \times \mathrm{E}}{\mathrm{Cm}}
$$




$$
\begin{aligned}
& \quad=\frac{1,50 \mathrm{~m}^{3} \times 60 \times 0,83}{0,820 \text { menit }} \\
& =91,098 \mathrm{~m}^{3} / \mathrm{jam}
\end{aligned}
$$

\section{e. Produksi Water Tanker}

Merek / Tipe

Volume tangki air (V)

Kebutuhan air $/ \mathrm{m}^{3}(\mathrm{~W})$

Pengisian tangki air/jam (n)

Efisiensi alat (E)

Taksiran Produksi Alat (Q)

$$
\begin{aligned}
\mathrm{Q} & =\frac{\mathrm{V} \times \mathrm{n} \times \mathrm{E}}{\mathrm{W}} \\
& =\frac{4,00 \times 3 \times 0,83}{0,70} \\
=14,229 \mathrm{~m}^{3} / \mathrm{jam} &
\end{aligned}
$$

\section{f. Produksi Motor Grader}

Merek / Tipe

Panjang blade (Le)

Lebar tumpah tindih (Lo)

Kecepatan kerja (V)

Faktor efisiensi kerja (E)

Taksiran Produksi Alat (Q)
: DA. 110.3

: $4,00 \mathrm{~m}^{3}$

: $0,70 \mathrm{~m}^{3}$

: 3 kali

: 0,83 (tabel. 1)

$$
\begin{aligned}
\mathrm{Q} & =\mathrm{V}(\mathrm{Le}-\mathrm{Lo}) \times 1000 \times \mathrm{E} \\
& =1,6 \mathrm{~km} / \mathrm{jam}(0,71) \times 1000 \times 0,83=942,880 \mathrm{~m}^{2} / \mathrm{jam}
\end{aligned}
$$

\section{g. Produksi Dump Truck}

Merek / type

Kapasitas bak (V)

Kapasitas bucket (KB)

Jarak angkut (L)

Kec. Rata-rata bermuatan (V1)

Kec. Rata-rata kosong (V2)

Faktor efisiensi kerja (E)

Waktu siklus $(\mathrm{Cm})$ :
: Komatsu G-27

: 3,10 m (tabel 6)

: 2,39 $\mathrm{m}($ tabel 6$)$

: $1,6 \mathrm{~km} / \mathrm{jam}($ tabel 5$)$

: 0,83 (tabel 1.)

$>$ Waktu muat (LT)

jumlah siklus yang dibutuhkan alat pemuat (excavator) untuk mengisi dumptruck

cms alat pemuat (excavator) $=0,820$

$$
\mathrm{N}=\frac{\text { Kapasitas rata }- \text { rata dump truck }}{\text { Kapasitas bucket } \times \text { Faktor bucket }} \mathrm{N}=\frac{4,00 \mathrm{~m}^{3}}{1,50 \times 0,80}=3,333
$$

Waktu muat $(\mathrm{LT}) \quad=\mathrm{N} \times \mathrm{cms}$

$$
=3,333 \times 0,820=2,733 \text { menit }
$$

Waktu angkut (T1)

$$
=\frac{\mathrm{L}}{\mathrm{V} 1}=\frac{1000 \mathrm{~m}}{500 \mathrm{~m} / \mathrm{jam}}=2 \text { menit }
$$

Waktu kembali (T2) 


$$
=\frac{\mathrm{L}}{\mathrm{V} 2}=\frac{1000 \mathrm{~m}}{833,333 \mathrm{~m} / \mathrm{jam}}=1,2 \text { menit }
$$

Waktu buang (DT)

DT $=1,15$ menit (rata-rata), (tabel. 3)

Waktu mengambil posisi antri (SDT)

SDT $=0,3$ menit (rata-rata) (tabel. 4 )

Jadi : $\mathrm{Cm}=\mathrm{LT}+\mathrm{T} 1+\mathrm{T} 2+\mathrm{DT}+\mathrm{SDT}$

$=2,733+2+1,2+1,15+0,3$

$=7,383$ menit

$\underline{\text { Taksiran Produksi Alat }(\mathrm{Q}) \text { : }}$

$$
\begin{aligned}
Q & =\frac{V \times 60 \times E}{C \mathrm{Cm}^{3}} \\
& =\frac{4,00 \mathrm{~m}^{3} \times 60 \times 0,83}{7,383 \mathrm{menit}} \\
& =26,981 \mathrm{~m}^{3} / \mathrm{jam}
\end{aligned}
$$

\subsection{Hasil Perhitungan Waktu Pelaksanaan Alat Yang Digunakan \\ Pekerjaan Mobilisasi}

Untuk Menghitung waktu yang dibutuhkan dalam pekerjaan mobilisasi ini maka dapat dihitung menggunakan rumus yaitu :

$$
\mathrm{D}=\frac{\mathrm{V}}{\mathrm{Q}}
$$

\section{a. Produksi Excavator}

Dimana:

$\mathrm{V}=$ Volume pekerjaan mobilisasi $=1 \mathrm{LS}$

$\mathrm{Q}=$ Produksi excavator dalam tiap jam $=21 \mathrm{~m}^{3} / \mathrm{jam}$

Maka, waktu yang diperlukan adalah:

$$
\begin{aligned}
\mathrm{D} & =\frac{1 \mathrm{LS}}{21 \mathrm{~m}^{3} / \mathrm{jam}} \\
& =47,619 \mathrm{jam}
\end{aligned}
$$

Excavator beroperasi dalam satu hari 8 jam, maka waktu yang dibutuhkan adalah:

$$
\begin{aligned}
\mathrm{D} & =\frac{47,619}{8 \text { jam } / \text { hari }} \\
& =5,952(6 \text { hari })
\end{aligned}
$$

\section{b. Produksi Vibrator Roller}

Dimana:

$\mathrm{V}=$ Volume pekerjaan mobilisasi $=1 \mathrm{LS}$

$\mathrm{Q}=$ Produksi vibrator roller dalam tiap jam $=155,625 \mathrm{~m}^{3} / \mathrm{jam}$

Maka, waktu yang diperlukan adalah:

$$
\text { } \mathrm{D}=\frac{1 \mathrm{LS}}{155,625 \mathrm{~m}^{3} / \mathrm{jam}}
$$

Vibrator Roller beroperasi dalam satu hari 8 jam, maka waktu yang dibutuhkan adalah: 


$$
\begin{aligned}
\mathrm{D} & =\frac{6,426 \text { jam }}{8 \text { jam } / \text { hari }} \\
& =8,032 \text { (8 hari })
\end{aligned}
$$

\section{c. Produksi Wheel Loader}

Dimana:

$\mathrm{V}=$ Volume pekerjaan mobilisasi $=1 \mathrm{LS}$

$\mathrm{Q}=$ Produksi wheel loader dalam tiap jam $=90,545 \mathrm{~m}^{3} / \mathrm{jam}$

Maka, waktu yang diperlukan adalah:

$$
\begin{aligned}
\mathrm{D} & =\frac{1 \mathrm{LS}}{90,545 \mathrm{~m}^{3} / \mathrm{jam}} \\
& =11,044 \mathrm{jam}
\end{aligned}
$$

Wheel Loader beroperasi dalam satu hari 8 jam, maka waktu yang dibutuhkan adalah:

$$
\begin{aligned}
\mathrm{D} & =\frac{11,044 \text { jam }}{8 \text { jam } / \text { hari }} \\
& =1,381(2 \text { hari })
\end{aligned}
$$

\section{d. Produksi Water Tanker}

Dimana:

$\mathrm{V}=$ Volume pekerjaan mobilisasi $=1 \mathrm{LS}$

$\mathrm{Q}=$ Produksi water tanker dalam tiap jam $=14,229 \mathrm{~m}^{3} / \mathrm{jam}$

Maka, waktu yang diperlukan adalah:

$$
\begin{aligned}
\mathrm{D} & =\frac{1 \mathrm{LS}}{14,229 \mathrm{~m}^{3} / \mathrm{jam}} \\
& =70,279 \mathrm{jam}
\end{aligned}
$$

Water Tanker beroperasi dalam satu hari 8 jam, maka waktu yang dibutuhkan adalah:

$$
\begin{aligned}
\mathrm{D} & =\frac{70,279 \mathrm{jam}}{8 \mathrm{jam} / \mathrm{hari}} \\
& =8,785(9 \text { hari })
\end{aligned}
$$

\section{e. Produksi Motor Grader}

Dimana:

$\mathrm{V}=$ Volume pekerjaan mobilisasi $=1 \mathrm{LS}$

$\mathrm{Q}=$ Produksi motor grader dalam tiap jam $=942,880 \mathrm{~m}^{2} / \mathrm{jam}$

Maka, waktu yang diperlukan adalah:

$$
\begin{aligned}
\mathrm{D} & =\frac{1 \mathrm{LS}}{942,880 \mathrm{~m}^{2} / \mathrm{jam}} \\
& =1,061 \mathrm{jam}
\end{aligned}
$$

Motor Grader beroperasi dalam satu hari 8 jam, maka waktu yang dibutuhkan adalah:

$$
\mathrm{D}=\frac{1,061 \mathrm{jam}}{8 \mathrm{jam} / \text { hari }}=1,326(2 \text { hari })
$$

\section{f. Produksi Dump Truck}

Dimana: 
$\mathrm{V}=$ Volume pekerjaan mobilisasi $=1 \mathrm{LS}$

$\mathrm{Q}=$ Produksi dump truck dalam tiap jam $=26,981 \mathrm{~m}^{3} / \mathrm{jam}$

Maka, waktu yang diperlukan adalah:

$$
\begin{aligned}
\mathrm{D} & =\frac{1 \mathrm{LS}}{26,981 \mathrm{~m}^{3} / \mathrm{jam}} \\
& =37,063 \mathrm{jam}
\end{aligned}
$$

Dump Truck beroperasi dalam satu hari 8 jam, maka waktu yang dibutuhkan adalah:

$$
\begin{aligned}
\mathrm{D} & =\frac{37,063 \text { jam }}{8 \text { jam } / \text { hari }}=4,633 \\
& \left.=\frac{4,633}{28 \text { dump truck }}=16,5 \text { (17 hari }\right)
\end{aligned}
$$

\section{Pekerjaan Timbunan Biasa dari Sumber Galian}

Untuk Menghitung waktu yang dibutuhkan dalam pekerjaan mobilisasi ini maka dapat dihitung menggunakan rumus yaitu :

$$
\mathrm{D}=\frac{\mathrm{V}}{\mathrm{Q}}
$$

\section{a. Produksi Excavator}

Dimana:

$\mathrm{V}=$ Volume pekerjaan timbunan biasa dari sumber galian $=149.053 \mathrm{~m}^{3}$

$\mathrm{Q}=$ Produksi excavator dalam tiap jam $=21 \mathrm{~m}^{3} / \mathrm{jam}$

Maka, waktu yang diperlukan adalah:

$$
\begin{aligned}
\mathrm{D} & =\frac{149,053 \mathrm{~m}^{3}}{21 \mathrm{~m}^{3} / \mathrm{jam}} \\
& =7,097 \mathrm{jam}
\end{aligned}
$$

Excavator beroperasi dalam satu hari 8 jam, maka waktu yang dibutuhkan adalah:

$$
\begin{aligned}
\mathrm{D} & =\frac{7,097 \text { jam }}{8 \text { jam } / \text { hari }} \\
& =88,722 \text { (89hari) }
\end{aligned}
$$

\section{b. Produksi Dump Truck}

Dimana:

$\mathrm{V}=$ Volume pekerjaan timbunan biasa dari sumber galian $=149.053 \mathrm{~m}^{3}$

$\mathrm{Q}=$ Produksi dump truck dalam tiap jam $=26,981 \mathrm{~m}^{3} / \mathrm{jam}$

Maka, waktu yang diperlukan adalah:

$$
\begin{aligned}
\mathrm{D} & =\frac{149,053 \mathrm{~m}^{3}}{26,981 \mathrm{~m}^{2} / \mathrm{jam}} \\
& =5,524 \mathrm{jam}
\end{aligned}
$$

Dump Truck beroperasi dalam satu hari 8 jam, maka waktu yang dibutuhkan adalah:

$$
\begin{aligned}
\mathrm{D} & =\frac{5,524 \text { jam }}{8 \text { jam } / \text { hari }}=690,546 \text { jam } \\
& =\frac{690,546}{28 \text { dump truck }}=246,624 \text { (247 hari) }
\end{aligned}
$$




\section{c. Produksi Motor Grader}

Dimana:

$\mathrm{V}=$ Volume pekerjaan timbunan biasa dari sumber galian $=149.053 \mathrm{~m}^{3}$

$\mathrm{Q}=$ Produksi motor grader dalam tiap jam $=942,880 \mathrm{~m}^{2} / \mathrm{jam}$

Maka, waktu yang diperlukan adalah:

$$
\begin{aligned}
\mathrm{D} & =\frac{149,053 \mathrm{~m}^{3}}{942,880 \mathrm{~m}^{2} / \mathrm{jam}} \\
& =158,083 \mathrm{jam}
\end{aligned}
$$

Motor Grader beroperasi dalam satu hari 8 jam, maka waktu yang dibutuhkan adalah:

$$
\begin{aligned}
\mathrm{D} & =\frac{158,083 \text { jam }}{8 \text { jam } / \text { hari }} \\
& =19,760 \text { (20 hari })
\end{aligned}
$$

\section{d. Produksi Vibrator Roller}

Dimana:

$\mathrm{V}=$ Volume pekerjaan timbunan biasa dari sumber galian $=149.053 \mathrm{~m}^{3}$

$\mathrm{Q}=$ Produksi vibrator roller dalam tiap jam $=155,625 \mathrm{~m}^{3} / \mathrm{jam}$

Maka, waktu yang diperlukan adalah:

$$
\begin{aligned}
\mathrm{D} & =\frac{149,053 \mathrm{~m}^{3}}{155,625 \mathrm{~m}^{3} / \mathrm{jam}} \\
& =957,770 \mathrm{jam}
\end{aligned}
$$

Vibrator Roller beroperasi dalam satu hari 8 jam, maka waktu yang dibutuhkan adalah:

$$
\begin{aligned}
\mathrm{D} & =\frac{957,770 \text { jam }}{8 \text { jam } / \text { hari }} \\
& =119,721 \text { (120 hari })
\end{aligned}
$$

\section{e. Produksi Water Tanker}

Dimana:

$\mathrm{V}=$ Volume pekerjaan timbunan biasa dari sumber galian $=149.053 \mathrm{~m}^{3}$

$\mathrm{Q}=$ Produksi water tanker dalam tiap jam $=14,229 \mathrm{~m}^{3} / \mathrm{jam}$

Maka, waktu yang diperlukan adalah:

$$
\begin{aligned}
\mathrm{D} & =\frac{149,053 \mathrm{~m}^{3}}{14,229 \mathrm{~m}^{3} / \mathrm{jam}} \\
& =10,475 \mathrm{jam}
\end{aligned}
$$

Water Tanker beroperasi dalam satu hari 8 jam, maka waktu yang dibutuhkan adalah:

$$
\begin{aligned}
\mathrm{D} & =\frac{10,475 \text { jam }}{8 \text { jam } / \text { hari }} \\
& =130,941(131 \text { hari })
\end{aligned}
$$


Tabel 3.1. Jadwal Mobilisasi dan Penggunaan Alat

\begin{tabular}{|c|c|c|c|c|c|}
\hline No & Uraian Pekerjaan & Jenis Peralatan & Satuan & $\begin{array}{l}\text { Perkiraan } \\
\text { Kuantitas }\end{array}$ & $\begin{array}{c}\text { Durasi } \\
\text { (Hari) }\end{array}$ \\
\hline & Divisi 1. Umum & & & & \\
\hline \multirow[t]{8}{*}{1} & Mobilisasi & & LS & 1,00 & 28 \\
\hline & & Excavator & Unit & 6,00 & 28 \\
\hline & & Vibrator Roller & Unit & 2,00 & 14 \\
\hline & & Wheel Loader & Unit & 2,00 & 14 \\
\hline & & Water Tanker & Unit & 2,00 & 14 \\
\hline & & Motor Grader & Unit & 2,00 & 14 \\
\hline & & Dump Truck & Unit & 28,00 & 28 \\
\hline & Divisi 3. Pekerjaan Tanah & & & & \\
\hline \multirow[t]{7}{*}{2} & $\begin{array}{l}\text { Timbunan Biasa dari Sumber } \\
\text { Galian }\end{array}$ & & $\mathrm{m}^{3}$ & $149,053,02$ & 287 \\
\hline & & Excavator & Unit & 6,00 & 287 \\
\hline & & Dump Truck & Unit & 28,00 & 287 \\
\hline & & Motor Grader & Unit & 2,00 & 287 \\
\hline & & Vibrator Roller & Unit & 2,00 & 287 \\
\hline & & Water Tanker & Unit & 2,00 & 287 \\
\hline & $\begin{array}{c}\text { Jumlah Perkiraan Kuantitas } \\
\text { Alat Berat }\end{array}$ & & & 42,00 & \\
\hline
\end{tabular}

(Sumber : Data Proyek, 2019)

Tabel 3.2. Jadwal Mobilisasi dan Penggunaan Alat

\begin{tabular}{|c|c|c|c|c|c|}
\hline No & Uraian Pekerjaan & Jenis Peralatan & Satuan & $\begin{array}{l}\text { Perkiraan } \\
\text { Kuantitas }\end{array}$ & $\begin{array}{c}\text { Durasi } \\
\text { (Hari) }\end{array}$ \\
\hline & Divisi 1. Umum & & & & \\
\hline \multirow[t]{9}{*}{1} & Mobilisasi & & LS & 1,00 & 17 \\
\hline & & Truck Trailer/Tronton & Unit & - & - \\
\hline & & Excavator & Unit & 6,00 & 6 \\
\hline & & Vibrator Roller & Unit & 2,00 & 8 \\
\hline & & Wheel Loader & Unit & 2,00 & 2 \\
\hline & & Water Tanker & Unit & 2,00 & 9 \\
\hline & & Motor Grader & Unit & 2,00 & 2 \\
\hline & & Dump Truck & Unit & 28,00 & 17 \\
\hline & Divisi 3. Pekerjaan Tanah & & & & \\
\hline \multirow[t]{7}{*}{2} & $\begin{array}{l}\text { Timbunan Biasa dari Sumber } \\
\text { Galian }\end{array}$ & & $\mathrm{m}^{3}$ & $149,053,02$ & 247 \\
\hline & & Excavator & Unit & 6,00 & 89 \\
\hline & & Dump Truck & Unit & 28,00 & 247 \\
\hline & & Motor Grader & Unit & 2,00 & 20 \\
\hline & & Vibrator Roller & Unit & 2,00 & 120 \\
\hline & & Water Tanker & Unit & 2,00 & 131 \\
\hline & $\begin{array}{c}\text { Jumlah Perkiraan Kuantitas } \\
\text { Alat Berat }\end{array}$ & & & 42,00 & \\
\hline
\end{tabular}

(Sumber : Hasil Perhitungan Penulis,2020) 


\section{Pembahasan}

Berdasarkan data yang diperoleh dari hasil penelitian dan analisis perhitungan dengan menggunakan perhitungan produktivitas alat berat dan perhitungan waktu kerja peralatan sesuai dengan spesifikasi yang ditentukan dalam dokumen kontrak, waktu yang dibutuhkan dalam pekerjaan mobilisasi yaitu 28 hari setelah dilakukan perhitungan kembali, pekerjaan tersebut dapat dikerjakan selama 17 hari atau lebih cepat 11 hari dalam menyelesaikan pekerjaan mobilisasi dengan menggunakan alat berat dan begitu juga dengan pekerjaan yang lain, pada pekerjaan timbunan biasa dari sumber galian waktu yang dibutuhkan dalam pekerjaan yaitu 287 hari namun setelah dilakukan perhitungan kembali waktu yang dibutuhkan hanya 247 hari atau lebih cepat 40 hari dalam menyelesaikan pekerjaan, Namun dalam setiap pekerjaan yang melibatkan alat berat waktu pekerjaan belum tentu berjalan sesuai dengan yang direncanakan karena pasti ada hambatan-hambatan yang terjadi dilokasi proyek misalnya seperti alat berat yang rusak atau medan lokasi yang sulit untuk alat berat beroperasi sehingga waktu tidak berjalan sesuai dengan jadwal yang direncanakan.

Begitu pula ada hambatan-hambatan yang terjadi pada proyek lanjutan reklamasi dan jalan kawasan kayu merah-kalumata ini, seperti perlu dilakukan pengawalan pada jalan yang dilalui oleh dump truck menuju ke tempat pengambilan material sehingga dapat lebih mempercepat pengambilan material dan juga tidak menganggu lalu lintas yang mengakibatkan kemacetan yang begitu parah, dan pekerja lapangan dari kontraktor agar dapat menempatkan peralatan di lokasi proyek dengan teratur tanpa menganggu pelaksanaan pekerjaan, dengan demikian waktu pelaksanaan pekerjaan menjadi lebih efisien dan perlu juga ditetapkan suku cadang dari alat berat yang dibutuhkan sehingga sewaktu-waktu apabila alat berat tersebut rusak maka dapat langsung diperbaiki, dengan demikian kelengkapan pekerjaan dapat terjamin dan proyek dapat selesai dengan jadwal yang direncanakan.

\subsection{KESIMPULAN}

Berdasarkan hasil penelitian dan analisis pada proyek pembangunan reklamasi dan jalan kawasan kayu merahkalumata ini di dapat beberapa kesimpulan, yaitu :

1. Produktivitas dari setiap model alat berat pada pekerjaan mempunyai produktivitas yang berbeda-beda, seperti truck trailer/tronton memiliki produktivitas 60,614 menit, excavator memiliki produktivitas $21 \mathrm{~m}^{3} / \mathrm{jam}$, vibrator roller memiliki produktivitas $155,625 \mathrm{~m}^{3} / \mathrm{jam}$, wheel loader memiliki produktivitas $91,098 \mathrm{~m}^{3} / \mathrm{jam}$, water tanker memiliki produktivitas $14,229 \mathrm{~m}^{3} / \mathrm{jam}$, motor grader memiliki produktivitas $942,880 \mathrm{~m}^{2} / \mathrm{jam}$, dan dump truck memiliki produktivitas $26,981 \mathrm{~m}^{3} / \mathrm{jam}$.

2. Hasil yang diperoleh dalam perhitungan dan efisiensi waktu yang terjadi yaitu :

a. Pada pekerjaan mobilisasi alat yang digunakan seperti excavator membutuhkan waktu 6 hari, alat berat vibrator roller membutuhkan waktu 8 hari, alat berat wheel loader membutuhkan waktu 2 hari, alat berat water tanker membutuhkan waktu 9 hari, alat berat motor grader membutuhkan waktu 2 hari, dan alat berat dump truck membutuhkan waktu 17 hari, maka setelah di analisa waktu yang dibutuhkan dalam menyelesaikan pekerjaan mobilisasi yaitu membutuhkan waktu 17 hari atau lebih cepat dari waktu yang telah direncanakan dalam dokumen kontrak yaitu 28 hari.

b. Pada pekerjaan timbunan biasa dari sumber galian alat yang digunakan seperti excavator membutuhkan waktu 89 hari, alat berat dump truck membutuhkan waktu 247 hari, alat berat motor grader membutuhkan waktu 20 hari, alat berat vibrator roller membutuhkan waktu 120 hari, dan alat berat water tanker membutuhkan waktu 131 hari maka setelah di analisa waktu yang dibutuhkan dalam menyelesaikan pekerjaan timbunan biasa dari sumber galian yaitu membutuhkan waktu 247 hari atau lebih cepat dari waktu yang telah direncanakan dalam dokumen kontrak yaitu 287 hari.

\section{Ucapan Terima Kasih}

Ucapan terima kasih disampaikan kepada semua pihak yang telah berperan dalam penelitian analisis produktivitas waktu kerja alat berat pada pembangunan lanjutan reklamasi dan jalan kawasan kayu merahkalumata) sehingga penelitian ini dapat di selesaikan dengan baik.

\section{References}

[1] Agus Salim, 2014. Analisis Efisiensi Produktivitas Waktu Kerja Alat Berat Pada Pembangunan Jalan (Studi Kasus: Ruas Jalan Tangkeh-Blang Luah Cs, Woyla Timur), Fakultas Teknik Universitas Teuku Umar, Aceh Barat. 
[2] Djoko Wilopo, 2011. Metode Konstruksi dan Alat-alat Berat. Fakultas Teknik, Universitas Indonesia, Jakarta.

[3] Nunnally, S.W, 2007. Construction Methods and Management, Seventh Edition, Pearson Education, New York.

[4] Peurifoy, R.L, 2006. Construction Planning, Equipment, and Methods, Seventh Edition. Mc Graw Hill, lnc.

[5] Rochmanhadi, 1982. Alat Berat Dan Kegunaannya, Badan Penerbit Departemen Pekerjaan Umum, Jakarta.

[6] Rochmanhadi, 1985. Perhitungan Biaya Pelaksanaan Pekerjaan Dengan Menggunakan Alat Berat, Badan Penerbit Departemen Pekerjaan Umum, Jakarta.

[7] Soedrajat, 1982. Efisiensi Penggunaan Alat Berat Pada Pengaspalan Jalan Raya, Nova, Jakarta.

[8] Susi Fatena Rostiyanti, 2002. Alat Berat Untuk Proyek Konstruksi, PT. Rineka Cipta, Jakarta. 